\title{
Psicodinâmica do trabalho: a dialética do prazer e sofrimento em residentes multiprofissionais de um hospital de ensino
}

\author{
Psychodynamics of work: the dialectic pleasure and suffering in \\ multidisciplinary residents of a teaching hospital
}

\section{Psicodinámica del trabajo: el placer y el sufrimiento en dialéctica residente multiprofesional un hospital universitario}

\author{
Nelson Silva Rodrigues Junior ${ }^{1}$ \\ Carla Vaz dos Santos Ribeiro ${ }^{2}$
}

\begin{abstract}
RESUMO: O presente estudo objetivou investigar as vivências de prazer e sofrimento no processo de formação de residentes multiprofissionais de um hospital de ensino. A investigação foi desenvolvida dentro da abordagem de pesquisa quantitativa, utilizando-se o método descritivo exploratório. A coleta de dados realizou-se com aplicação de questionário de caracterização social e profissional dos participantes e a Escala de Prazer e Sofrimento no Trabalho (EPST), validada e aplicada por Mendes (1999). Como referencial teórico para análise dos resultados utilizou-se a psicodinâmica do trabalho, que exprime o confronto do sujeito com a realidade do trabalho e suas consequências na dinâmica dos processos psíquicos. Os resultados demonstraram que a valorização é vivenciada de forma intensa pelos residentes; os maiores índices foram em relação à finalidade do trabalho e à exigência de conhecimentos específicos para este. Quanto ao desgaste, este sentimento também se obteve presente, porém em menor intensidade. $\mathrm{O}$ maior fator de desgaste foi relacionado ao cansaço e ao desgaste no trabalho. $\mathrm{O}$ fator reconhecimento demonstrou que os residentes sentem-se reconhecidos, onde os maiores índices de reconhecimento foram relacionados à convivência com os colegas e à possibilidade de utilização do estilo pessoal no ambiente de trabalho. Os resultados remetem a uma reflexão sobre a dialética prazer e sofrimento no ambiente de trabalho, e revelam itens significativos para os residentes multiprofissionais, em relação ao seu ambiente de formação e de trabalho, abrindo espaço para discussões e produção de medidas que auxiliem a administração do prazer e sofrimento de forma sadia neste processo de formação.
\end{abstract}

Palavras-chave: Capacitação em Serviço, Internato e Residência, Princípio do Prazer-Desprazer, Psicoterapia Psicodinâmica, Trabalho.

\begin{abstract}
The present study aimed to investigate the experiences of pleasure and suffering in the process of training multi-professional residents of a teaching hospital. The research was developed within the quantitative research approach, using the exploratory descriptive method. Data collection was carried out with the application of a questionnaire of social and professional characterization of the participants and the Scale of Pleasure and Suffering at Work (EPST), validated and applied by Mendes (1999). As a theoretical reference for the analysis of results it was used the

\footnotetext{
1 Psicólogo e Fisioterapeuta. Possui Residência Multiprofissional em Saúde (UFMA). Especialização em Educação Permanente em Saúde (UFRGS). Especialização em Saúde Mental e Atenção Psicossocial (FAR) - Universidade Federal do Maranhão - UFMA - São Luís, Maranhão, Brasil. E-mail: nelson_rodrigues_jr@hotmail.com 2 Psicóloga. Possui Doutorado em Psicologia Social (UERJ). Mestrado em Psicologia Social (UERJ). Especialização em Psicologia do Trabalho (UNESA). Professora adjunta da Graduação e do Mestrado em Psicologia - Universidade Federal do Maranhão- UFMA. Maranhão, Brasil. E-mail: carlavazribiero@uol.com.br
}

ISSN 1982-8829 Tempus, actas de saúde colet, Brasília, 11(3), 193-215, 2017 - Epub mar, 2018 
psychodynamics of work, which expresses the confrontation of the subject with the reality of work and its consequences in the dynamics of psychic processes. The results showed that the valuation is intensely experienced by the residents; the highest indexes were in relation to the purpose of the work and the requirement of specific knowledge for it. As for wear, this feeling was also present, although with less intensity. The greatest wear factor was related to fatigue and wear at work. The recognition factor demonstrated that the residents feel recognized, where the highest recognition rates were related to the coexistence with colleagues and the possibility of using personal style in the workplace. The results refer to a reflection on the dialectic of pleasure and suffering in the work environment, revealing significant items for multi-professional residents, in relation to their training environment and work, opening space for discussions and the production of measures that help the administration of the pleasure and suffering in a healthy way in this process of formation. Keywords: In-service Training, Internship and Residency, Pleasure-Pain Principle, Psychotherapy Psychodynamic, Work.

RESUMEN: Este estudio tuvo como objetivo investigar las experiencias de placer y sufrimiento en multidisciplinaria proceso de formación de los residentes de un hospital universitario. La investigación se llevó a cabo en el enfoque de la investigación cuantitativa, utilizando el método exploratorio descriptivo. La recolección de datos se llevó a cabo con un cuestionario de caracterización social y profesional de los participantes y la Escala de placer y sufrimiento en el trabajo (EPST), validado y aplicado por Mendes (1999). Como marco teórico para el análisis de los resultados se utilizó la psicodinámica del trabajo, que expresa la confrontación del sujeto con la realidad del trabajo y sus consecuencias sobre la dinámica de los procesos psíquicos. Los resultados mostraron que la recuperación se experimenta intensamente por los residentes; las tasas más altas fueron en relación con los propósitos y la exigencia de un conocimiento específico para esto. Para el desgaste, este sentimiento también consiguió esto, pero a una intensidad menor. El factor de mayor desgaste se relaciona con la fatiga y el desgaste en el trabajo. El factor de reconocimiento mostró que los residentes sienten reconocidos, donde las tasas de reconocimiento más altos se relacionan con la convivencia con los compañeros y la posibilidad de uso de estilo personal en el lugar de trabajo. Los resultados apuntan a una reflexión sobre el placer dialéctica y el sufrimiento en el lugar de trabajo, y revelan elementos significativos para los residentes multidisciplinarios en relación con su formación y medio ambiente de trabajo, por lo que las habitaciones de los debates y de producción de medidas para ayudar a la administración de el placer y el sufrimiento de una manera saludable en este proceso de formación.

Palavras clave: Capacitación en Servicio, Internado y Residencia, Principio de Dolor-Placer, Psicoterapia Psicodinámica, Trabajo.

\section{INTRODUÇÃO}

A necessidade de superação do modelo clínico tradicional de atenção à saúde no Brasil, para o surgimento de ações que desencadeiem processos de mudanças, precisa repercutir nas formas de trabalho no setor da saúde. Sob esse enfoque, foram propostas reavaliações na formação, por meio de reformas curriculares e nos métodos de ensino, bem como na qualificação dos trabalhadores que já estavam inseridos nos serviços de saúde através da elaboração de programas permanentes de aperfeiçoamento de pessoal ${ }^{1}$.

Neste contexto, a residência é considerada uma modalidade de ensino que utiliza como metodologia a formação em serviço, no nível de pós-graduação latu-sensu ${ }^{2}$. As residências

ISSN 1982-8829 Tempus, actas de saúde colet, Brasília, 11(3), 193-215, 2017 - Epub mar, 2018 
multiprofissionais são caracterizadas como um processo de formação a partir da inserção no trabalho. Essa metodologia é fundamental no preparo de trabalhadores qualificados para a atenção à saúde da população e para a reorganização do processo de trabalho em saúde 3 .

As residências multiprofissionais promovem um contato entre o mundo do trabalho e o mundo da formação, que possibilitam mudanças no modelo tecnoassistencial a partir da atuação multiprofissional ou integrada adequada às necessidades locorregionais. Constitui um processo de educação permanente em saúde que possibilita a afirmação do trabalhador em seu universo de trabalho e na sociedade em que vive ${ }^{4}$. É nesse contato com o mundo do trabalho por meio do ensino em serviço, que o residente multiprofissional passa a ser reconhecido como trabalhador de saúde, deixando de ser apenas aluno.

Com o exposto, considerando que esse processo de formação é caracterizado como um preparo para o trabalho, vários desafios emergem desta modalidade de formação. Segundo Dejours ${ }^{5}$, o contexto atual do trabalho, marcado por grandes mudanças e instabilidade, propiciou um cenário no qual o sofrimento psíquico, as descompensações psíquicas e somáticas, os acidentes de trabalho e o adoecimento físico e psíquico dos trabalhadores se tornaram presentes.

A proposição do estudo originou-se a partir de vivências do autor nesse processo de formação, no qual se observou que apesar de seu caráter transformador, visando romper com os paradigmas em relação à formação de profissionais para o Sistema Único de Saúde (SUS), alguns de seus aspectos podem gerar grande sobrecarga psíquica, resultante de os residentes multiprofissionais lidarem diariamente com dilemas e encargos relacionados à atividade das suas respectivas profissões, que exigem grande preparo e responsabilidades, tais como: a convivência diária com pacientes graves e situações críticas no ambiente hospitalar, atividades relacionadas às disciplinas teóricas, dentre outras tarefas que podem interferir no estabelecimento de limites entre a vida pessoal e profissional, devido ao tempo dedicado ao trabalho.

Para tanto, tornou-se importante conhecer as situações de prazer e de sofrimento vivenciadas pelos residentes. Tais situações relacionam-se à abordagem da psicodinâmica do trabalho, na qual o trabalho é caracterizado como fonte de prazer e sofrimento, visto que estas emoções permeiam o processo de formação desta modalidade de ensino.

Assim, considerando-se a importância da temática proposta para a formação, fica evidente que esta é uma área de investigação que precisa ser potencializada e pode contribuir, a partir da identificação das situações de prazer e de sofrimento vivenciadas pelos residentes, com elementos para o planejamento de ações para a melhoria do processo de formação da residência multiprofissional em saúde.

O objetivo geral da pesquisa é investigar as vivências de prazer e sofrimento no processo 
de formação de residentes multiprofissionais de um hospital de ensino. Tendo como objetivos específicos: Descrever a caracterização social e profissional dos residentes multiprofissionais participantes da pesquisa e identificar os fatores que os residentes multiprofissionais de um hospital de ensino reconhecem como fontes de prazer e sofrimento em seu processo de formação.

Para a devida contextualização teórica, apresenta-se um breve histórico sobre o conceito de trabalho e reflexões acerca deste como categoria central. Caracterização sobre as residências multiprofissionais em saúde é o tópico que sucede. Segue-se um item sobre a psicodinâmica do trabalho, resgatando alguns de seus fundamentos, com enfoque no prazer e sofrimento no trabalho. A seguir, são resumidas as reflexões desenvolvidas por meio da aplicação da pesquisa. Considerações finais fecham o texto.

\section{O trabalho como categoria central}

Desde a Antiguidade até os dias atuais, o trabalho adquiriu - e vem adquirindo- significados diversos para a humanidade, apresentando peculiaridades de acordo com o contexto histórico.

Por muito tempo a concepção de trabalho foi associada a uma visão negativa, de fardo e tortura. Em sua própria etimologia, o termo origina-se do latim tripalium, cujo significado preciso é "instrumento feito de três paus aguçados, algumas vezes ainda munidos de pontas de ferro, nas quais agricultores bateriam o trigo, as espigas de milho, o linho, para rasgá-los e esfiapá-los"6. $\mathrm{Na}$ Idade Média esse instrumento acabou por tornar-se um instrumento de tortura inquisional, atribuindo-se uma conotação de sofrimento ${ }^{7}$.

$\mathrm{Na}$ Grécia Antiga o termo trabalho sequer existia. As atividades laboriosas eram realizadas pelos escravos, os inferiores. Mesmo sem um termo que o definisse na época, o trabalho era considerado atividade vil e indigna, causador essencialmente de sofrimento em detrimento do ócio, pai da felicidade e filho da liberdade ${ }^{8}$.

Os tempos mudaram, e uma nova concepção de trabalho passou a vigorar, não sendo mais uma condição servil. A partir do Renascimento, ganhou uma concepção positiva relacionada à possibilidade de construção, de identidade e de autorrealização. Segundo Albornoz', "as razões para trabalhar estão no próprio trabalho e não fora dele ou em qualquer de suas consequências". Nesse contexto, trabalho ganha também um novo sentido: o preenchimento da vida do homem.

Hoje, de acordo com a Declaração Universal dos Direitos Humanos ${ }^{9}$ em seu artigo XXIII "toda pessoa tem direito ao trabalho, à livre escolha de emprego, a condições justas e favoráveis de trabalho e à proteção contra o desemprego". Nesses tempos de mudança da escravidão a servidão voluntária, o trabalho antes visto como dever e sofrimento inevitável passa a ser representado como direito que garante a dignidade do homem. Ganhando assim uma categoria central na sociedade ocidental $^{10}$. 
Dejours ${ }^{11}$ afirma que o trabalho, além de ter um caráter de julgamento utilitário, significa, para o trabalhador, uma forma de afirmar sua identidade, a sua realização e o seu reconhecimento. Dessa forma, o sentido atribuído pelos indivíduos ao trabalho é composto pela utilidade para a organização e para a sociedade, relacionado com as ideias de finalidade e objetivo.

No entanto, o trabalho nem sempre funciona como fonte de crescimento, reconhecimento e independência profissional e, muitas vezes, ele gera insatisfação, irritação, exaustão e adoecimento ${ }^{12}$. Dejours, Dessors e Desriaux ${ }^{13}$ apontam que o trabalho pode gerar desgastes, mas que é também um fator essencial para o equilíbrio e o desenvolvimento do ser humano, importando nesta relação não tanto qual trabalho seja realizado, mas sim quais as condições para a realização deste.

Nesse contexto cabe reforçar a dupla face do trabalho proveniente da dicotomia dessa atividade humana, no qual segundo Seligmann-Silva ${ }^{14}$, "funciona como fonte de construção, satisfação, realização, riqueza, bens materiais e serviços úteis à sociedade humana, mas que, também pode significar escravidão, exploração, sofrimento, doença e morte".

Considerando as várias dimensões e a complexidade da relação do homem com o trabalho, compreende-se a dialética existente no viés ideológico que o trabalho perpassa na vida do homem; ora tendo um caráter vital na existência dos indivíduos, ora sendo adquirindo um espaço de manifestações de sintomas que afetam na saúde do trabalhador.

\section{Residências multiprofissionais em saúde: Um processo de formação em serviço para qualificação do SUS}

A origem da modalidade de ensino denominada residência está diretamente relacionada ao significado dicionarizado da palavra - moradia. Historicamente, um dos requisitos básicos aos candidatos desse tipo de curso era o de residir na instituição onde se desenvolvia o programa de educação em serviço, e os alunos deveriam estar à disposição do hospital em tempo integral ${ }^{15}$.

Os primeiros programas de residência surgiram dentro de instituições hospitalares e em regime de internato. A residência médica, enquanto modalidade de ensino legalmente reconhecida em serviço de pós-graduação, foi pioneira na área da saúde, surgindo nos Estados Unidos da América (EUA) no fim do século XIX. No Brasil, a residência médica iniciou em 1940 e consolidou-se em 1960, influenciada pelo modelo americano e centrada no modelo hegemônico tradicional, baseado no treinamento e habilidades técnicas nas instituições hospitalares ${ }^{16}$.

A primeira residência multiprofissional do Brasil surgiu em 1977 na Escola de Saúde Pública do Rio Grande do Sul (ESP/RS) - O programa de residência em saúde comunitária da Unidade Sanitária São José do Murialdo ${ }^{17}$. Tinha como proposta o trabalho em equipe multiprofissional, mediante o cuidado prestado à saúde da população na rede básica de saúde, ultrapassando a 
assistência à saúde focada no cuidado médico ao corpo biológico ${ }^{16}$.

O Ministério da Saúde vem apoiando a modalidade de residência multiprofissional em saúde desde 2002, quando foram criadas 19 residências multiprofissionais em saúde da família, com financiamento desse órgão, "dentro da perspectiva de trabalhar integradamente com todas as profissões da saúde" ${ }^{18}$.

Residências multiprofissionais e/ou integradas em saúde só começaram a ser regulamentadas em 2005, quando foi promulgada a Lei $\mathrm{N}^{\circ} 11.129$, de 30 de junho de 2005, que criou a residência em área profissional da saúde e instituiu a Comissão Nacional de Residência Multiprofissional em Saúde (CNRMS) ${ }^{3}$.

A Portaria Interministerial $n^{\circ}$. 2.117, instituiu no âmbito do Ministério da Saúde e da Educação, a residência multiprofissional em saúde ${ }^{19}$. Em consonância, no ano de 2007, a Portaria Interministerial $\mathrm{n}^{\mathrm{o}}$. 45 reconheceu a residência multiprofissional em saúde como curso de especialização caracterizado por ensino em serviço ${ }^{20}$.

Diante do exposto, pode-se concluir que o histórico dos programas de residência, não é recente e que gradualmente elas vêm se configurando e consolidando quanto uma pós-graduação latu-sensu, contribuindo para a formação de trabalhadores de saúde de acordo com as exigências do SUS, representando uma das estratégias potenciais para repensar o processo de formação em saúde.

\section{Psicodinâmica do trabalho e prazer e sofrimento no trabalho: Um constructo dialético}

Criada em 1990 na França por Christophe Dejours, a psicodinâmica do trabalho, de início, com as bases da psicopatologia e depois evoluindo como uma abordagem científica autônoma deuse a partir do estudo da normalidade, sobre o da patologia. A psicodinâmica do trabalho propõe uma abordagem além da teoria e da pesquisa, sendo também um modo de ação na organização do trabalho ${ }^{21}$.

O objeto da psicodinâmica do trabalho é o estudo das relações dinâmicas entre organização do trabalho e processos de subjetivação, que se manifestam nas vivências de prazer e sofrimento, em estratégias que sinalizam incoerências no ambiente de trabalho, doenças na sociedade e aspectos envolvendo adoecimento e saúde no trabalho ${ }^{21}$.

Para a psicodinâmica, o trabalho apresenta um papel de grande relevância na estruturação da saúde psíquica de um indivíduo, quando este permite diminuir a sua energia pulsional; entretanto, quando não possibilita a descarga pulsional, torna-se fatigante, fonte de adoecimento ${ }^{22}$.

O trabalho pode ser tanto fonte de prazer como de sofrimento; isto vai depender da mediação ISSN 1982-8829 Tempus, actas de saúde colet, Brasília, 11(3), 193-215, 2017 - Epub mar, 2018 
entre a subjetividade do trabalhador e das suas condições de trabalho ${ }^{23}$. Para a psicodinâmica do trabalho, prazer e sofrimento são indissociáveis, e o trabalho contribui para subverter sofrimento em prazer a partir de condições sociais, políticas e éticas da organização e dos processos de trabalho ${ }^{24}$.

Derivado do verbo em latim, placere, que significa agradar parecer bem, o termo prazer, também está relacionado ao termo placare, que significa "aquietar, acalmar". A expressão prazer no trabalho, abordada pela psicodinâmica do trabalho, define prazer como um princípio mobilizador da dinâmica que emerge dos contextos de trabalho. Define-se prazer como um princípio mobilizador que recoloca o sujeito em ação para a busca da gratificação, realização de si e reconhecimento pelo outro da utilidade e beleza do seu trabalho ${ }^{24}$.

O termo sofrimento no trabalho tem sua origem na psicanálise, na acepção empregada por Freud em 1996 na obra "A Psicopatologia da Vida Cotidiana", em que pathos se refere ao estudo do sofrimento e não apenas, da doença ${ }^{25}$. O sofrimento do trabalho é inerente ao confronto do sujeito com o real do trabalho, decorrente da defasagem irredutível entre organização prescrita e o real. Nem sempre um modo de operar assimilado e elaborado funciona adequadamente. O trabalho traz sempre surpresas, inesperados, incidentes, anomalias, que põem em xeque as previsões e predições $^{26}$.

O sofrimento, dependendo dos processos psicodinâmicos desenvolvidos no trabalho, pode se encaminhar em dois destinos: o criativo e o patogênico. Este ocorre quando o sujeito não encontra possibilidade de negociação entre a organização de trabalho e os seus conteúdos subjetivos, ficando impedido de exercitar sua capacidade criadora; persistindo a vivência de fracasso que consequentemente irá comprometer a saúde. Já o sofrimento criativo, acontece quando o sofrimento pode atuar como um mobilizador para mudanças, impulsionando para a busca de soluções através da criação e da "engenhosidade" ${ }^{27}$.

A saúde psíquica segundo a psicodinâmica, não é decorrência apenas da ausência de sofrimento, como também da existência de possibilidades internas e externas capazes de propiciarem ao trabalhador meio de transformação do sofrimento pela tomada de consciência de suas causas, dos seus conflitos e das situações que o geraram ${ }^{28}$.

O desafio, não é eliminar o sofrimento e, sim, definir ações que favoreçam a transformação e a ressignificação das situações geradoras de desprazer em situações geradoras de prazer $^{29}$.

Conforme pode-se inferir, o prazer-sofrimento abordado pela psicodinâmica do trabalho, trata-se de uma vivência dialética, que não pode ser estudada separadamente. O que pode se identificar são os aspectos específicos da organização do trabalho que ora favorecem uma, ora a outra vivência, assim como a dinâmica delas decorrente.

A configuração da situação de trabalho como prazerosa ou não, segundo Torres e Abrahão ${ }^{30}$, 
está relacionada ao modo como o trabalhador lida com tal situação. As variáveis 'prazer' e 'sofrimento' são resultantes da relação do indivíduo com a organização, consigo mesmo, com outros indivíduos e com o meio no qual está inserido. Assim, o que para uns pode ser fonte se prazer não será necessariamente para outros.

\section{METODOLOGIA}

A investigação foi desenvolvida dentro da abordagem da pesquisa quantitativa, utilizandose o método descritivo exploratório.

O estudo foi realizado na cidade de São Luís, no estado do Maranhão, com profissionais residentes de um programa de Residência Multiprofissional em Saúde de um hospital de ensino. O programa caracteriza-se como um curso de pós-graduação latu-sensu, com duração de dois anos, 60 horas semanais de atividades, sendo $80 \%$ atividades práticas e $20 \%$ atividades teóricas, perfazendo uma carga horária total de 5760 horas-aula.

Esse processo de formação é realizado sob regime de dedicação exclusiva. Para tanto, os residentes recebem uma bolsa mensal, a qual é viabilizada mediante o cumprimento da carga horária exigida. O programa abrange as seguintes áreas de formação: enfermagem, odontologia, fisioterapia, psicologia, nutrição, educação física, fonoaudiologia, serviço social, terapia ocupacional e farmácia.

O instrumento para coletar os dados foi a Escala de Prazer e Sofrimento no Trabalho (EPST), validada e aplicada por Mendes ${ }^{31}$ em sua tese de doutoramento, que teve como base a aplicação da escala de Likert. Esse instrumento é composto por 39 afirmativas no qual os entrevistados, utilizam da escala assinalando graus de concordância. A escala possui cinco intervalos pontuados de 1 a 5, correspondendo: "1" a afirmativa "nunca"; "2" a "raramente"; "3" a "às vezes"; "4" a "frequentemente"; e "5" a "sempre". Estas 39 afirmativas são distribuídas em 3 fatores: valorização, desgaste e reconhecimento, distribuídas do seguinte modo:

Valorização: questões $01,04,07,10,13,16,19,22,27,30,33,35,37,38$ e 39.

Desgaste: questões 02, 05, 08, 11, 14, 17, 20, 23, 25, 28, 31, 34 e 36.

Reconhecimento: questões 03, 06, 09, 12, 15, 18, 21, 24, 26, 29 e 32.

Seguindo as recomendações da criadora da escala, a análise das médias é realizada com base na distribuição normal, sendo a partir da comparação entre as médias obtidas, a definição dos resultados para cada um dos fatores representativos da presença ou ausência de prazer e sofrimento no trabalho.

Como qualquer intervalo de classe possui seu ponto médio, definido como valor mais central do mesmo, utilizou-se a seguinte fórmula para determiná-la:

ISSN 1982-8829 Tempus, actas de saúde colet, Brasília, 11(3), 193-215, 2017 - Epub mar, 2018 
Limite inferior + limite superior $/ 2=1+5 / 2=3$

Os participantes também responderam a um questionário para levantamento de dados sóciodemográficos. O mesmo tinha por finalidade garantir uma maior compreensão do sujeito da pesquisa por meio da caracterização pessoal e profissional. Foram incluídos aspectos como sexo, idade, estado civil, presença de filhos e dependentes, escolaridade (curso, instituição de ensino superior, ano de conclusão) e tempo de trabalho anterior à residência multiprofissional.

A coleta de dados foi realizada nos meses de junho e julho de 2015 e adotou-se como critério para inclusão na pesquisa: Ser profissional residente do segundo ano da Residência Multiprofissional em Saúde matriculado no programa de Atenção à Saúde do Adulto e do Idoso do biênio 2014-2016 e ter consentido em participar da pesquisa.

As informações encontradas foram organizadas e agrupadas segundo a natureza de suas variáveis e convertidas em tabelas demonstrativas contendo médias, medianas, variância e desvio padrão dos escores referentes aos fatores de valorização, desgaste e reconhecimento da EPST.

Este estudo foi realizado em consonância com a resolução 466/2012 do Conselho Nacional de Saúde do Ministério da Saúde, que discorre sobre a pesquisa com seres humanos. Nesse sentido, a execução do presente trabalho foi pautado no pressuposto da autonomia dos sujeitos e na garantia de sigilo das informações que permitam a identificação dos participantes da pesquisa.

Ainda consoante com a resolução supracitada, este estudo foi aprovado pelo Comitê de Ética em Pesquisa do Hospital Universitário da Universidade Federal do Maranhão sob número de parecer 1.064.603, em de 15 de maio de 2015.

\section{RESULTADOS E DISCUSSÃO}

\section{Caracterização pessoal e profissional dos residentes multiprofissionais}

De um total de 42 residentes multiprofissionais matriculados no programa, tornaram-se participantes da pesquisa 40 residentes distribuídos nas seguintes categorias: 10 enfermeiros, 7 fisioterapeutas, 4 nutricionistas, 4 farmacêuticos, 3 terapeutas ocupacionais, 3 odontólogos, 1 educador físico, 2 assistentes sociais, 4 psicólogos e 2 fonoaudiólogos. Logo obteve-se um total de $95,23 \%$ de participantes do estudo.

Em relação à caracterização pessoal dos residentes, observa-se na Tabela 1, o predomínio do sexo feminino $(77,75 \%)$, em sua maioria solteiros $(87,5 \%)$, sem filhos $(87,5 \%)$ e sem dependentes (77,5\%), com a faixa etária entre 23 a 26 anos (70\%). 
Tabela 1: Caracterização pessoal dos residentes multiprofissionais

\begin{tabular}{c|l|c|c}
\hline Variáveis & & $\mathbf{N = 1 0}$ & $\mathbf{\%}$ \\
\hline \multirow{2}{*}{ Sexo } & Feminino & 31 & 77,5 \\
& Masculino & 9 & 22,5 \\
\hline \multirow{2}{*}{ Idade } & $23-26$ anos & 28 & 70 \\
& $27-30$ anos & 10 & 25 \\
& $31-34$ anos & 2 & 5 \\
Estado Civil & Solteiro & 35 & 87,5 \\
& Casado & 5 & 12,5 \\
\hline \multirow{2}{*}{ Número de Filhos } & Nenhum & 35 & 87,5 \\
& Mais de dois Filhos & 5 & 12,5 \\
& & 0 & 0 \\
\hline \multirow{2}{*}{ Dependentes } & Sim & 9 & 22,5 \\
economicamente & Não & 31 & 77,5 \\
\hline \multirow{2}{*}{ TOTAL } & & $\mathbf{4 0}$ & $\mathbf{1 0 0}$ \\
\hline
\end{tabular}

Os resultados vieram ao encontro daqueles identificados em pesquisa realizada por_Franco et al. ${ }^{32}$ (2011) com residentes de enfermagem, no qual a maioria da amostra compôs-se por mulheres $(81,3 \%)$, solteiras $(93,8 \%)$, sem filhos $(87,5 \%)$ e com idade média de 25,8 anos.

A predominância do sexo feminino na residência se relaciona com o crescimento da participação das mulheres no mercado de trabalho e principalmente a feminização do setor da saúde.

Dados do IBGE ${ }^{33}$ mostram a enorme expressão feminina na força de trabalho em saúde. Do total de 709.267 pessoas ocupadas no setor com escolaridade universitária, 61,75\% são mulheres. A categoria profissional mais feminizada é a dos nutricionistas, em que as mulheres correspondem a $95 \%$ dos profissionais, e enfermeiros que corresponde a $90 \%$.

Segundo Wegner e Pedro ${ }^{34}$ as mulheres têm conquistado espaços essenciais à sua valorização e afirmação social por meio dos papéis que vêm desempenhando com competência na família, na comunidade e no trabalho.

Em relação à idade dos residentes multiprofissionais estudados, a idade média foi de 27,9 
anos, com a predominância da faixa etária entre 23 a 26 anos. Este achado se assemelha ao estudo de Goulart, Silva, Bolzan e Guido ${ }^{35}$ sobre o perfil sociodemográfico e acadêmico de residentes multiprofissionais de uma universidade pública, em que se verificou a prevalência de residentes na faixa etária entre 25 a 29 anos. Esse perfil de residentes adultos jovens pode estar relacionado à maioria serem recém-formados.

No que se refere ao estado civil, são em sua maioria solteiros (87,5\%). O que está diretamente relacionado ao fato de em grande parte os residentes multiprofissionais não possuírem filhos, nem pessoas que dependem economicamente deles. Neste sentido, os achados deste estudo, podem remeter a opção pela formação profissional em detrimento da família.

Em relação à caracterização profissional dos residentes multiprofissionais, evidencia-se que os enfermeiros são a categoria profissional mais presente da residência (25\%), 42,5 \% são provenientes da Universidade Federal do Maranhão- UFMA, 72,5\% não possuem especialização, $52,5 \%$ nunca tiveram experiência de trabalho anterior ao processo de formação (Tabela 2).

Tabela 2: Caracterização profissional dos residentes multiprofissionais

\begin{tabular}{|c|c|c|c|}
\hline Variáveis & & $\mathbf{N}=\mathbf{1 0}$ & $\%$ \\
\hline $\begin{array}{c}\text { Categoria } \\
\text { Profissional }\end{array}$ & $\begin{array}{l}\text { Educação Física } \\
\text { Enfermagem } \\
\text { Farmácia } \\
\text { Fisioterapia } \\
\text { Fonoaudiologia } \\
\text { Nutrição } \\
\text { Odontologia } \\
\text { Psicologia } \\
\text { Serviço Social } \\
\text { Terapia Ocupacional }\end{array}$ & $\begin{array}{c}1 \\
10 \\
4 \\
7 \\
2 \\
4 \\
3 \\
4 \\
2 \\
3\end{array}$ & $\begin{array}{c}2,5 \\
25 \\
10 \\
17,5 \\
5 \\
10 \\
7,5 \\
10 \\
5 \\
7,5\end{array}$ \\
\hline $\begin{array}{l}\text { Instituição de } \\
\text { Ensino Superior }\end{array}$ & $\begin{array}{l}\text { Universidade Federal do } \\
\text { Maranhão- UFMA } \\
\text { Universidade Federal do } \\
\text { Piauí- UFPI } \\
\text { Universidade Estadual } \\
\text { do Piauí- UESPI } \\
\text { Faculdade } \\
\text { Terezinha- CEST } \\
\text { Universidade Ceuma } \\
\text { Faculdade do Maranhão- } \\
\text { FACAM Universitário } \\
\text { Centro Uninovafapi }\end{array}$ & $\begin{array}{l}17 \\
5 \\
2 \\
8 \\
6 \\
1 \\
1\end{array}$ & $\begin{array}{r}42,5 \\
12,5 \\
5 \\
20 \\
15 \\
2,5 \\
2,5\end{array}$ \\
\hline
\end{tabular}




\begin{tabular}{c|l|c|c}
\hline & Sim & 11 & 27,5 \\
Especialização & Não & 29 & 72,5 \\
\hline & Nunca trabalhei & 21 & 52,5 \\
Tempo de & Menos de 1 ano & 6 & 15 \\
Trabalho anterior & 1 a 2 anos & 3 & 7,5 \\
à Residência & Mais e 2 anos & 10 & 25 \\
\hline TOTAL & & 40 & 100 \\
\hline
\end{tabular}

A grande quantidade de enfermeiros na pesquisa (10) está relacionada à maior oferta de vagas do programa destinada à categoria. Por se tratar de uma formação realizada no hospital, há uma maior demanda desses profissionais.

Observa-se que em grande parte os residentes são egressos de universidades do estado em que foi realizada a referida pesquisa. A residência é o primeiro contato com o mundo do trabalho e o mundo de formação da maioria dos deles.

É notória a importância desse processo de formação na vida desses profissionais, em sua maioria recém-formados, que buscam por uma construção de sua identidade profissional e aperfeiçoamento importantes no preparo de profissionais qualificados para a atenção à saúde da população brasileira e para a reorganização do processo de trabalho em saúde na direção dos princípios e diretrizes constitucionais do SUS, conforme rege o Ministério da Saúde.

\section{Análise da escala de prazer e sofrimento no trabalho (EPST)}

A escala de prazer e sofrimento no trabalho apresenta a distribuição das perguntas de forma aleatória, na qual os três fatores propostos por Mendes ${ }^{31}$-valorização, reconhecimento, e desgastese encontram misturados. Para facilitar a análise, os itens foram organizados e agrupados em tabelas. Nas tabelas foram ordenados os valores de médias (Méd.), medianas (med.), variância (Var.), e desvio padrão (D.p.). Alguns itens da escala foram adaptados para tornarem-se questionamentos aplicáveis à realidade encontrada. Cada fator será analisado individualmente nos tópicos a seguir.

\section{Valorização}

Para Mendes ${ }^{31}$ "a valorização é o sentimento de que o trabalho tem sentido e valor por si mesmo, é importante e significativo para a organização e a sociedade".

A partir da análise dos escores observa-se vivência valorativa deste fator; que obteve o escore total de 4,01; média acima da média estipulada metodologicamente para predominância da vivência de prazer na forma de valorização no ambiente de trabalho (Tabela 3). 
Tabela 3: Distribuição das médias, medianas, variância e desvio padrão dos escores referentes ao fator valorização.

\begin{tabular}{|c|c|c|c|c|}
\hline Item & Méd. & med. & Var. & D.p. \\
\hline 07 Meu trabalho tem finalidade & 4,575 & 5 & 0,40 & 0,63 \\
\hline $\begin{array}{l}33 \text { Minhas tarefas exigem conhecimentos } \\
\text { específicos }\end{array}$ & 4,575 & 5 & 0,35 & 0,59 \\
\hline $\begin{array}{l}37 \text { Meu trabalho contribui para o } \\
\text { desenvolvimento da sociedade }\end{array}$ & 4,4 & 5 & 0,53 & 0,77 \\
\hline 01 Meu trabalho é importante para o hospital & 4,325 & 5 & 1,14 & 1,07 \\
\hline $\begin{array}{l}19 \text { Minhas tarefas são significativas para } \\
\text { mim }\end{array}$ & 4,325 & 5 & 0,58 & 0,76 \\
\hline 27 Sinto orgulho do trabalho que realizo & 4,15 & 5 & 0,64 & 0,80 \\
\hline $\begin{array}{l}39 \text { Minhas tarefas são significativas para as } \\
\text { pessoas em geral }\end{array}$ & 4,175 & 5 & 0,86 & 0,93 \\
\hline $\begin{array}{l}04 \text { Quando executo minhas tarefas realizo- } \\
\text { me profissionalmente }\end{array}$ & 4,05 & 5 & 0,81 & 0,90 \\
\hline 13 Sinto-me útil no meu trabalho & 4,05 & 5 & 0,76 & 0,87 \\
\hline 35 Identifico-me com minhas tarefas & 3,975 & 5 & 0,53 & 0,73 \\
\hline 30 Sinto-me produtivo no meu trabalho & 3,855 & 5 & 0,64 & 0,80 \\
\hline $\begin{array}{l}10 \text { Utilizo minha criatividade no desempenho } \\
\text { de minhas tarefas }\end{array}$ & 3,82 & 5 & 0,66 & 0,81 \\
\hline $\begin{array}{l}38 \text { Tenho disposição para realizar minhas } \\
\text { tarefas }\end{array}$ & 3,85 & 5 & 0,69 & 0,83 \\
\hline 22 Minhas tarefas não são banais & 3,175 & 5 & 2,30 & 0,80 \\
\hline $\begin{array}{l}16 \text { Consigo adaptar meu trabalho às minhas } \\
\text { necessidades }\end{array}$ & 3,025 & 5 & 0,89 & 0,94 \\
\hline Total & 4,01 & 5 & 0,78 & 0,81 \\
\hline
\end{tabular}

Segundo os autores Mendes e Tamayo ${ }^{36}$ ao sentir valorização, o trabalhador considera seu trabalho importante para si mesmo, para a empresa e a sociedade, indicando assim, um reforço ISSN 1982-8829 Tempus, actas de saúde colet, Brasília, 11(3), 193-215, 2017 - Epub mar, 2018 
positivo na autoimagem, que está relacionada ao orgulho pelo trabalho que faz à realização profissional, ao sentir-se útil e produtivo.

O maior escore obtido no fator valorização refere-se ao item 7 da EPST, "meu trabalho tem finalidade", atingindo 4,575. Conclui-se que, a maioria dos residentes multiprofissionais frequentemente sente que seu trabalho tem finalidade.

Também com escore de 4,575, o item 33 da EPST, "minhas tarefas exigem conhecimentos específicos", foi frequentemente encontrada no processo de formação da residência. Infere-se este resultado ao fato de que mesmo se encontrando na mesma unidade hospitalar, as atividades executadas requerem de práticas específicas de cada categoria profissional.

O menor escore obtido no fator valorização refere-se ao item 16 da EPST, "consigo adaptar meu trabalho às minhas necessidades", atingindo 3,02; que pela média estipulada metodologicamente corresponde à "às vezes".

\section{Desgaste}

Segundo Mendes ${ }^{31}$ "o sofrimento é vivenciado quando experimentado o desgaste em relação ao trabalho, que significa a sensação de cansaço, desânimo e descontentamento com o trabalho".

Por meio de médias (Méd.), medianas (med.), variância (Var.), e desvio padrão (D. P.) obtidos através da análise dos dados coletados na EPST, pode-se concluir com os escores obtidos no fator desgaste, que embora em menor escala, há existência deste sentimento no processo de formação de residência multiprofissional; o escore total $(3,01)$ encontra-se com quase a mesma média estipulada metodologicamente (3) para a predominância da vivencia de sofrimento na forma de desgaste no ambiente de trabalho.

Tabela 4: Distribuição das médias, medianas, variância e desvio padrão dos escores referentes ao fator desgaste.

\begin{tabular}{l|cccc}
\hline \multicolumn{1}{c|}{ Item } & Méd. & med. & Var. & D.p. \\
\hline 02 Meu trabalho é cansativo & 3,625 & 5 & 1 & 1,00 \\
\hline $\begin{array}{l}\text { 08 Meu trabalho é desgastante } \\
\text { N5 Sinto-me sobrecarregado no meu trabalho }\end{array}$ & 3,275 & 5 & 0,87 & 0,93 \\
\hline $\begin{array}{l}\text { 28 A repetitividade das minhas tarefas me } \\
\text { incomoda }\end{array}$ & 3,175 & 5 & 1,27 & 1,12 \\
\hline $\begin{array}{l}\text { 23 Revolta-me a submissão da preceptoria às } \\
\text { ordens superiores }\end{array}$ & 3,15 & 5 & 2,02 & 1,42 \\
\hline
\end{tabular}




\begin{tabular}{l|cccc} 
14 Tenho frustrações com meu trabalho & 3,10 & 5 & 1,06 & 1,03 \\
$\begin{array}{l}\text { 05 Sinto-me injustiçado pelo sistema de } \\
\text { promoção do hospital }\end{array}$ & 3,05 & 5 & 1,79 & 1,33 \\
$\begin{array}{l}\text { 36 Fico revoltado quando tenho que submeter } \\
\text { meu trabalho às decisões políticas }\end{array}$ & 3,02 & 5 & 1,76 & 1,32 \\
$\begin{array}{l}\text { 31 Sinto desânimo no meu trabalho } \\
\text { 34 Meu trabalho me causa sofrimento }\end{array}$ & 3,00 & 5 & 0,87 & 0,93 \\
\hline $\begin{array}{l}\text { 17Permaneço na residência multiprofissional } \\
\text { por falta de oportunidade no mercado }\end{array}$ & 2,6 & 5 & 0,76 & 0,87 \\
\hline $\begin{array}{l}\text { 11 Não sinto satisfação no meu trabalho } \\
\text { 20 Minhas tarefas são desagradáveis }\end{array}$ & 2,4 & 5 & 1,16 & 1,08 \\
\hline \begin{tabular}{l} 
Total \\
\hline
\end{tabular} & 2,3 & 5 & 0,57 & 0,57 \\
\hline
\end{tabular}

O maior fator desgaste foi obtido nos itens 20, "meu trabalho é cansativo"(3,62), e 8, "meu trabalho é desgastante" $(3,5)$. Os resultados podem estar relacionados à alta carga horária semanal que os residentes precisam cumprir em treinamento em serviço semanalmente.

Os cursos de Residência da Área de Saúde no Brasil possuem uma carga horária de 60 horas semanais, sendo esta uma característica específica desta modalidade de formação em conjunto com as queixas frequentes dos ex-alunos sobre o número elevado de horas destes $\operatorname{cursos}^{37}$.

O menor escore obtido no fator desgaste foi no item 20 da EPST "minhas tarefas são desagradáveis", com média 2.3. Resultado esse, revela que de uma forma geral os residentes multiprofissionais raramente tem a sensação de que suas atribuições no hospital são desagradáveis ainda que se sintam desgastados.

\section{Reconhecimento}

Para Mendes ${ }^{31}$ "o reconhecimento é o sentimento de ser aceito e admirado no trabalho e ter a liberdade para expressar sua individualidade". Segundo Dejours ${ }^{27}$ quando a dinâmica do reconhecimento funciona, o sujeito se beneficia de uma retribuição simbólica que pode inscreverse no âmbito da realização do ego, no campo social.

Partindo da análise do resultado obtido no fator reconhecimento da EPST, observa-se a prevalência do sentimento de reconhecimento entre os residentes multiprofissionais; o escore total 
do fator reconhecimento foi 3,22, e encontra-se acima da média metodologicamente estipulada.

Tabela 5: Distribuição das médias, medianas, variância e desvio padrão dos escores referentes ao fator reconhecimento.

\begin{tabular}{|c|c|c|c|c|}
\hline Item & Méd. & med. & Var. & D.p. \\
\hline $\begin{array}{l}29 \text { Gosto de conviver com meus colegas no } \\
\text { trabalho }\end{array}$ & 4,075 & 5 & 1,04 & 1,02 \\
\hline 12 No meu trabalho uso meu estilo pessoal & 3,575 & 5 & 1,07 & 1,03 \\
\hline $\begin{array}{l}06 \text { Tenho autonomia no desempenho das } \\
\text { minhas tarefas }\end{array}$ & 3,55 & 5 & 1,07 & 1,03 \\
\hline 24 No meu trabalho posso ser eu mesmo & 3,525 & 5 & 1,64 & 1,28 \\
\hline 15 Sinto meus colegas solidários comigo & 3,35 & 5 & 1,10 & 1,05 \\
\hline $\begin{array}{l}18 \text { O tipo de trabalho que faço é admirado } \\
\text { pelos outros }\end{array}$ & 3,00 & 5 & 0,66 & 0,81 \\
\hline $\begin{array}{l}03 \text { Sinto o reconhecimento dos meus colegas } \\
\text { pelo trabalho que realizo }\end{array}$ & 2,975 & 5 & 0,84 & 0,91 \\
\hline $\begin{array}{l}21 \text { Tenho liberdade para organizar meu } \\
\text { trabalho da forma que quero }\end{array}$ & 2,975 & 5 & 1,46 & 1,20 \\
\hline $\begin{array}{l}26 \text { No meu trabalho participo desde o } \\
\text { planejamento até a execução das tarefas }\end{array}$ & 2,875 & 5 & 1,65 & 1,28 \\
\hline $\begin{array}{l}09 \text { Tenho liberdade para dizer o que penso } \\
\text { sobre meu trabalho }\end{array}$ & 2,85 & 5 & 1,10 & 1,05 \\
\hline $\begin{array}{l}32 \text { Sinto o reconhecimento da preceptoria } \\
\text { pelo trabalho que realizo }\end{array}$ & 2,725 & 5 & 1,02 & 1,01 \\
\hline Total & 3,22 & 5 & 1,15 & 1,06 \\
\hline
\end{tabular}

O maior escore obtido no fator reconhecimento foi 4,07 no item 29 "Gosto de conviver com meus colegas no trabalho". Reiterando Dejours ${ }^{38}$, trabalhar é conviver é "viver junto". Nesse sentido ressalta-se a importância de se conviver de forma agradável com os colegas de trabalho e que este ambiente seja saudável.

O menor escore obtido no fator reconhecimento foi 3,27 no item 32 "sinto o reconhecimento da preceptoria pelo trabalho que realizo". 
Para $\mathrm{Mendes}^{39}$, para que o trabalho seja fonte de prazer e consiga ressignificar o sofrimento, transformando-o em realização, faz-se necessário o engajamento do trabalhador. Porém, para esse engajamento é necessário o reconhecimento. Sem o reconhecimento, só há sofrimento patogênico, perde-se o sentido do trabalho, o prazer e a capacidade de reapropriação em relação à alienação. Quando o esforço do trabalhador que se caracteriza pela sua contribuição à organização do trabalho passa despercebido, conduz a um sofrimento que é muito perigoso à saúde mental ${ }^{40}$.

\section{CONSIDERAÇÕES FINAIS}

A pesquisa propôs-se investigar as vivências de prazer e sofrimento no processo de formação de residentes multiprofissionais de um hospital de ensino. Além de descrever a caracterização social e profissional destes e identificar quais fatores que os residentes reconhecem como fontes de prazer e sofrimento em seu processo de formação.

Diante do exposto, observou-se pela caracterização pessoal dos residentes multiprofissionais, que os mesmos são em sua maioria do sexo feminino, solteiros, sem filhos, com faixa etária entre 23 a 26 anos. Em relação à caracterização profissional, a residência representa a primeira qualificação profissional e contato com o mundo do trabalho. A categoria de enfermagem foi a mais encontrada, pela maior oferta de vagas no programa.

O enfoque da psicodinâmica do trabalho por meio da aplicação da escala EPST mostra vivências de prazer e sofrimento no processo de formação de uma residência multiprofissional em saúde. Os resultados demonstram que o prazer-sofrimento não são excludentes, confirmando o aspecto dialético do constructo apresentado na teoria.

O fator desgaste EPST foi encontrado ainda que em menor escala. Os maiores escores foram nos itens 20, "meu trabalho é cansativo" $(3,62)$, e 8 , "meu trabalho é desgastante" (3,5). As vivências de sofrimento estão associadas às características inerentes ao trabalho que o residente está sujeito ao longo dessa formação. Os resultados indicam um alerta para que sejam desenvolvidas medidas que reduzam os fatores causadores de cansaço e sobrecarga, que consequentemente, podem gerar desânimo e descontentamento com o trabalho.

Obteve-se vivência positiva do fator de valorização no trabalho desenvolvido pelos residentes. Os escores com maior evidência foram no item 7 , "meu trabalho tem finalidade" $(4,575)$ e o item 33, "minhas tarefas exigem conhecimentos específicos"(4,575).

O fator de reconhecimento também foi encontrado de forma valorativa pelos residentes. O maior escore obtido neste foi de 4,07 no item 29 "Gosto de conviver com meus colegas no trabalho". Destaca-se também o menor escore obtido no fator reconhecimento no item 32 "sinto o 
reconhecimento da preceptoria pelo trabalho que realizo" $(3,27)$.

As vivências moderadas de prazer, obtidas nos fatores de reconhecimento e valorização, são bastante positivas, pois servem de fator de neutralização para as vivências de sofrimento no trabalho.

A aplicação da escala justificou-se pelo interesse em se fazer uma descrição de um grande grupo de residentes em seu ápice de momento de processo de formação. Ainda que a escolha de apenas uma propriedade quantitativa tenha sido usada, considerando que este campo de investigação científica de organizações e trabalho necessita de técnicas mistas de coletas de dados para assim trabalharmos conceitos mais subjetivos, os objetivos foram atingidos.

Os resultados obtidos abrem novas perspectivas para uma investigação dos porquês, já que a escala permitiu um ponto gerador dos sentimentos, mas não possibilitou justificá-los, por não aprofundar e clarificar a natureza e intensidade das relações entre os três fatores analisados, através das questões que eram assinaladas de acordo com o grau de concordância do participante.

Fica, portanto, o desafio de futuras investigações empíricas sob as diferentes perspectivas metodológicas, de forma a avançar no entendimento tanto dos processos de adoecimento, quanto do desenvolvimento da saúde no contexto do trabalho em uma residência multiprofissional.

\section{REFERÊNCIAS}

1 Brasil. Lei n 8080, de 19 de setembro de 1990. Dispõe sobre as condições para a promoção, proteção e recuperação da saúde, a organização e o funcionamento dos serviços correspondentes e dá outras providências. [Internet]. [Acesso em: 11 nov. 2015]. Disponível em: https://www.planalto.gov.br/ccivil_03/leis/L8080.htm

2 Ceccim RB, Ferla AA. Residência integrada em saúde: uma resposta da formação e desenvolvimento profissional para montagem do projeto de integralidade da atenção à saúde. In: Pinheiro R, Mattos RA, organizadores. Construção da integralidade: cotidiano, saberes e práticas em saúde. Rio de Janeiro: Hucitec/Abrasco, 2003, p. 211-224.

3 Brasil. Ministério da Saúde. Relatório da Plenária do Seminário Nacional sobre Residências Multiprofissionais em Saúde. 01 e 02 de dezembro de 2005. Brasília, Hotel São Marcos. 2005d.

4 Ceccim RB. Residências em saúde: as muitas faces de uma especialização em área profissional integrada Ao SUS. In: Fajardo AP, Rocha CM, Pasini VL (Orgs.). Residências em saúde: fazeres \& saberes na formação em saúde. Porto Alegre: Hospital Nossa Senhora da Conceição; 2010. p: 17-22.

5 Dejours CA. Violência invisível. (Entrevista) Caros amigos, maio, 1999.

6 Albornoz S. O que é trabalho? São Paulo: Ed. Brasiliense, 1994.

7 Bonzatto EA. Tripalium: O trabalho como maldição, como crime e como punição. Direito em Foco, Amparo. 2011; $1: 1-37$

8 Chauí M. Introdução a O Direito à Preguiça, de Paul Lafargue. In: Santiago H. (Org.) Contra a servidão voluntária. Belo Horizonte/São Paulo: Autêntica/Fundação Perseu Abramo, 2013. v. 1. 
9. ONU. Declaração Universal dos Direitos Humanos. 1948, p.6.

10. Duarte FS, Mendes AM. Da escravidão a servidão voluntária: perspectivas para a clínica psicodinâmica do trabalho no Brasil. Revista Farol. 2015; 3: 68-128.

11. Dejours C. A psicodinâmica do trabalho na pós-modernidade. In: Mendes AM.; Lima SC da C.; Facas EP. (Org.) Diálogos em psicodinâmica do trabalho. Brasília: Paralelo 15, 2007; p. 13-26.

12. Dejours C. A loucura do trabalho: estudo de psicopatologia do trabalho (Paraguay AI; Ferreira LL, trads.) São Paulo: Cortez Oboré, 1992. 168 p.

13. Dejours C, Dessors D, Desriaux F. Por um trabalho, fator de equilíbrio. RAE. 1993; 33 (3): mai-jun.

14 Seligmann-Silva E. Saúde mental e trabalho. In: Cidadania e loucura - políticas de saúde mental no Brasil. Tundis AS, Costa NR. (orgs.). Rio de Janeiro: Vozes. $2^{\text {a }}$ Ed., 1990; p. 217-288.

15 Silveira A. (Coord.). Residência de Medicina do Trabalho - Programa 2005. Belo Horizonte: Universidade Federal de Minas Gerais. Serviço Especial de Saúde do Trabalhador do Hospital de Clínicas/Centro de Referência Estadual em Saúde do Trabalhador, jan. 2005. Disponível em: http:/www.hc.ufmg.br/crest/downloads/residencia_medicina trabalho.pdf Acesso em: 30 de junho de 2015.

16 Ferreira SR. Residência Integrada em Saúde: uma Modalidade de Ensino em Serviço. 2007. 127f. Dissertação (Mestrado em Enfermagem) - Universidade Federal do Rio Grande do Sul, Porto Alegre, 2007.

17 Ceccim RB, Armani TB. Educação em saúde coletiva: papel estratégico na gestão do SUS. Saúde para Debate, 2001 Rio de Janeiro, 23: 30-56, 2001.

18 Brasil. Residência Multiprofissional em Saúde: experiências, avanços e desafios [Internet]. Brasília (DF): Ministério da Saúde; 2006. [Acesso em 20 set. 2015]. Disponível em: http://bvsms.saude.gov.br/bvs/publicacoes/residencia multiprofissional.pdf

19. Ministério da Saúde e Ministério da Educação e Cultura (Brasil). Portaria Interministerial nº 2.117 de 3 de novembro de 2005. Institui no âmbito dos Ministérios da Saúde e da educação, a Residência Multiprofissional em Saúde e dá outras providências. Brasília. Diário Oficial União. 04 nov 2005; Seção 1:112. Disponível em: http://www.in.gov.br/ imprensa/visualiza/index.jsp?jornal=1\&pagina=112\&d ata=04/11/2005 Acesso em: 02 dez 2015.

20. Ministério da Educação Gabinete do Ministro (Brasil). Portaria interministerial no 45. Brasília-DF. $2007 \mathrm{~b}$. Disponível em: http://portal.mec.gov.br/index.php?option=com_docman\&view=download\&alias=15431-port-intern45-12jan-2007\&Itemid=30192 Acesso em: 02 dez 2015.

21 Mendes, AM, Ferreira MC. Inventário sobre Trabalho e Riscos de Adoecimento - ITRA: instrumento auxiliar de diagnóstico de indicadores críticos no trabalho. In: Mendes AMB. Psicodinâmica do trabalho: teoria, método e pesquisas. São Paulo: Casa do Psicólogo; 2007. p. 111-126.

22. Dejours C. A metodologia em psicopatologia do trabalho. In: Lancman S, Sznelwar L(Org.). Christophe Dejours: da psicopatologia à psicodinâmica do trabalho. Rio de Janeiro: Paralelo 15, Fiocruz; 2004a. p. 105-126.

23. Mendes AM, Borges LO, Ferreira MC. Trabalho em transição, saúde em risco. Brasília: Editora da Universidade de Brasília. 2002.

24. Mendes AM, Muller TC. Prazer no Trabalho. In: Vieira FO, Mendes AM, Merlo ARC. (Org). Dicionário Crítico de Gestão e Psicodinâmica do Trabalho. Curitiba: Juruá Editora; 2013. p. 289-292.

25. Moraes RD. Sofrimento Criativo e Patogênico. In: Vieira FO, Mendes AM, Merlo ARC. (Org). Dicionário Crítico de Gestão e Psicodinâmica do Trabalho. Curitiba: Juruá Editora; 2013. p. 289-292.

26. Dejours D. Addendum, da psicopatologia à psicodinâmica do trabalho, In: Lancman S, Sznelwar LI. (Org.). Christophe Dejours: da psicopatologia à psicodinâmica do trabalho. Brasília: Paralelo15, Fiocruz; 2004b. p. 47-104.

ISSN 1982-8829 Tempus, actas de saúde colet, Brasília, 11(3), 193-215, 2017 - Epub mar, 2018 
27. Dejours C. A psicodinâmica do trabalho na pós-modernidade. In: Mendes AM, Cruz SC, Facas EP (Org.). Diálogos em psicodinâmica do trabalho. Brasília: Paralelo 15; 2007.

28. Mendes AM. Cultura organizacional e prazer sofrimento no trabalho: uma abordagem psicodinâmica. In: Tamayo A. (Org.). Cultura e saúde nas organizações. Porto Alegre: Artmed; 2004. p. 59-76.

29. Dejours C, Abdoucheli E. Itinerário teórico em psicopatologia do trabalho. In: Dejours C, Abdoucheli E, Jayet C. (Org.) Psicodinâmica do trabalho: contribuições da escola dejouriana à análise da relação prazer, sofrimento e trabalho. São Paulo: Atlas; 1994. p. 119-145.

30 Torres CT, Abrahão JI. A atividade de teleatendimento: uma análise das fontes de prazer e sofrimento no trabalho. Rev. bras. saúde ocup. [Internet]. São Paulo (SP) 2006 jul.-dez. [Acesso em 28 nov. 2015]. 31(114): 113-124. Disponível em: http://www.scielo.br/scielo.php?script=sci_arttext\&pid=S0303-76572006000200010

31 Mendes AM. Valores e vivências de prazer-sofrimento no contexto organizacional. 1999. 306f. Tese (Doutorado em Psicologia) - Universidade de Brasília, Brasília, 1999.

32. Franco GP, Barros ALBL, Nogueira-Martins LA, Zeitoun SS. Burnout em residentes de enfermagem. Rev Esc Enferm USP [Internet]. 2011. [Acesso em 03 dez 2015]. 45(1): 12-8. Disponível em: http://www.scielo.br/pdf/reeusp/ v45n1/02.pdf

33. Instituto Brasileiro de Geografia e Estatística [homepage na internet]. Censo Demográfico, 2010 [Acesso em 12 dez 2015]. Disponível em: http:www.ibge.gov.br

34. Wegner W, Pedro ENR. Os múltiplos papéis sociais de mulheres cuidadoras-leigas de crianças hospitalizadas. Rev Gaúcha Enferm. [Internet]. Porto Alegre (RS) 2010 jun. [Acesso em 20 nov. 2015]. 31(2):335-42. Disponível em: http://www.scielo.br/pdf/rgenf/v31n2/19.pdf

35. Goulart CT, Silva RM, Bolzan MEO, Guido LA. Perfil sócio demográfico e acadêmico dos residentes multiprofissionais de uma universidade pública. Rev. RENE [Internet]. Fortaleza (CE) 2012. [Acesso em 01 out. 2015]; 13 (1): 178-186. Disponível em: http://www.revistarene.ufc.br/revista/index.php/revista/article/viewFile/29/25

36. Mendes AM., Tamayo A.Valores organizacionais e prazer-sofrimento no trabalho. Psico-USF [Internet]. 2001 jan./ jun. [Acesso em 10 out. 2015]; 6(1), 39-46. Disponível em: http://www.scielo.br/pdf/pusf/v6n1/v6n1a06.pdf

37. Lopes GT, Baptista SS. Residência de enfermagem: o cotidiano e seus desafios. In: Lopes GT (org.). Residência de enfermagem - espaços de lutas e contradições. Rio de Janeiro: EPUB, 2000. p.1-33

38. Dejours C. Subjetividade, trabalho e ação. Prod. [Internet]. São Paulo (SP) 2004 dez. [Acesso em 10 out. 2015 ]; 14 (3): 27-34. Disponível em: http://www.scielo.br/scielo.php?script=sci_arttext\&pid=S0103-65132004000300004\&lng $=$ pt\&nrm=iso

39. Mendes AM. (Org.). Trabalho e saúde: o sujeito entre emancipação e servidão. Curitiba: Juruá; 2008. p. 26-39.

40. Dejours C. Trajetória teórico-conceitual. In. Lancmann S, Sznelwar LI. (orgs) Christophe Dejours: da psicopatologia à psicodinâmica do trabalho. Brasília: Paralelo 15 / Rio de Janeiro: Editora Fiocruz; 2011.

\title{
APÊNDICE 1 - QUESTIONÁRIO DE CARACTERIZAÇÃO PESSOAL E PROFISSIONAL DOS RESIDENTES MULTIPROFISSIONAIS
}

1. Sexo:

\author{
( ) Feminino ( ) Masculino
}

2. Idade:

( ) 23- 26 anos

( ) 27- 30 anos

ISSN 1982-8829 Tempus, actas de saúde colet, Brasília, 11(3), 193-215, 2017 - Epub mar, 2018 
( ) 31- 34 anos

3. Estado civil:

( ) Solteiro (a) ( ) Casado (a)/companheiro (a)

( ) Separado (a)/divorciado (a) ( ) Viúvo (a)

4. Possui filho (a) (s)? Quantos?

( ) nenhum ( ) um a dois filhos ( ) mais de dois filhos

5. Existem pessoas que dependem economicamente de você?

( ) Sim ( ) Não

6. Formação Acadêmica:

A. Curso:

B. Instituição de Ensino Superior:

7. Possui Especialização?
( ) $\mathrm{Sim}$
( ) Não

8. Tempo de trabalho anterior à Residência Multiprofissional:
( ) nunca trabalhei
( ) menos de 1 ano
( ) 1 a 2 anos
( ) 2 anos
( ) mais de 2 anos

\section{ANEXO 1: ESCALA DE PRAZER- SOFRIMENTO NO TRABALHO (EPST)}

Leia as frases abaixo, analisando cada uma de acordo com o que você sente no dia a dia no trabalho como Residente Multiprofissional em Saúde. Marque, utilizando a escala abaixo, o número que melhor corresponde a sua avaliação.

\begin{tabular}{|l|c|c|c|c|c|}
\hline & $\begin{array}{c}1 \\
\text { Nunca }\end{array}$ & $\begin{array}{c}2 \\
\text { Raramente }\end{array}$ & $\begin{array}{c}3 \\
\text { Às vezes }\end{array}$ & Frequentemente & $\begin{array}{c}\text { Sempre } \\
\text { para o hospital é importante }\end{array}$ \\
\hline 2-Meu trabalho é cansativo & & & & & \\
\hline $\begin{array}{l}\text { 3-Sinto o reconhecimento do } \\
\text { meus colegas pelo trabalho } \\
\text { que realizo }\end{array}$ & & & & & \\
\hline $\begin{array}{l}\text { 4-Quando executo minhas } \\
\text { tarefas, realizo-me } \\
\text { profissionalmente }\end{array}$ & & & & & \\
\hline $\begin{array}{l}\text { 5-Sinto-me injustiçado pelo } \\
\text { sistema de promoção do } \\
\text { hospital }\end{array}$ & & & & & \\
\hline $\begin{array}{l}\text { 6-Tenho autonomia no } \\
\text { desempenho das minhas } \\
\text { tarefas }\end{array}$ & & & & & \\
\hline $\begin{array}{l}\text { 7-Meu trabalho tem } \\
\text { finalidade }\end{array}$ & & & & & \\
\hline
\end{tabular}




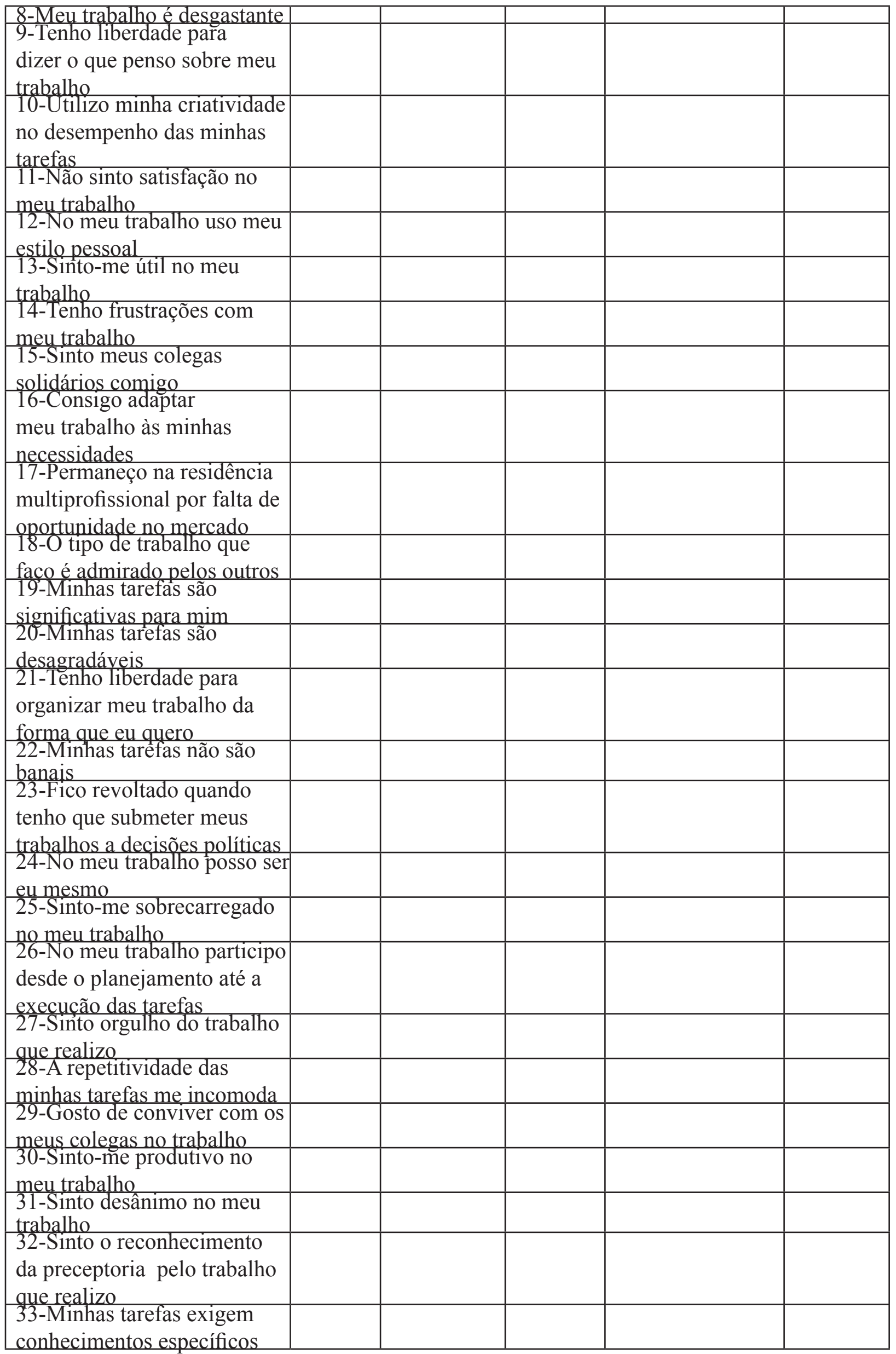




\begin{tabular}{|l|l|l|l|l|l|}
\hline $\begin{array}{l}\text { 34-Meu trabalho me causa } \\
\text { sofrimento }\end{array}$ & & & & & \\
\hline $\begin{array}{l}\text { 35-1dentifico-me com minhas } \\
\text { tarefas }\end{array}$ & & & & & \\
\hline $\begin{array}{l}\text { 36-Fico revoltado quando } \\
\text { tenho que submeter meu } \\
\text { trabalho a decjões políticas }\end{array}$ & & & & & \\
\hline $\begin{array}{l}\text { 37-Meu trabalho contribui } \\
\text { para o desenvolvimento da } \\
\text { sociedade }\end{array}$ & & & & & \\
\hline $\begin{array}{l}\text { 38-Tenho disposição para } \\
\text { realizar minhas tarefas }\end{array}$ & & & & & \\
\hline $\begin{array}{l}\text { 39-Minhas tarefas são } \\
\text { significativas para as pessoas } \\
\text { em geral }\end{array}$ & & & & & \\
\hline
\end{tabular}

Artigo apresentado em 08/01/2017

Artigo aprovado em 06/03/2018

Artigo publicado no sistema em 16/04/2018 